Optimization of Ultrasonic Fabric Cleaning

Federal Manufacturing \& Technologies

T. E. Hand

KCP-613-6078

Published May 1998

Final Report/Project Accomplishment Summary

CRADA Number 96-KCP-1044

Approved for public release; distribution is unlimited.

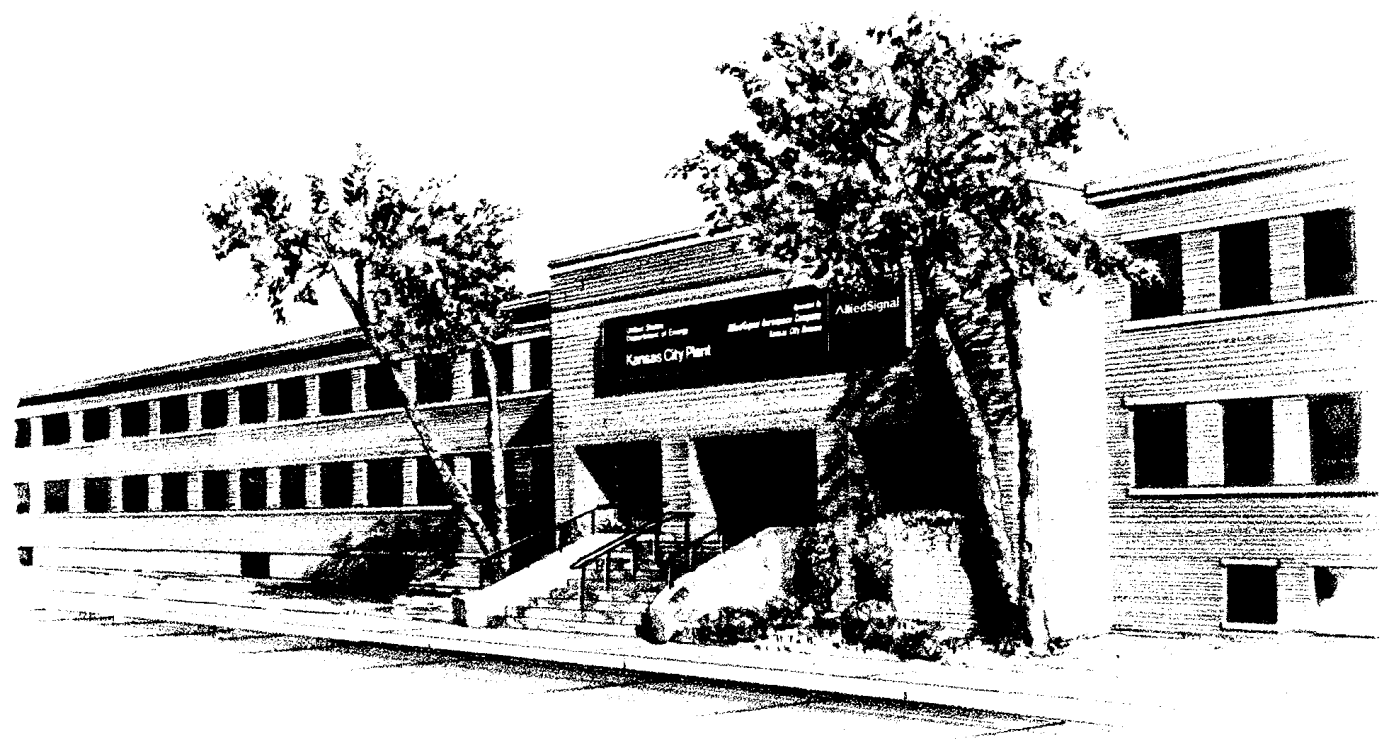

Pallatepared Under Contract Number DE-ACO4-76-DP00613 for the United States Department of Energy

\title{
DISCLAIMER
}

This report was prepared as an account of work sponsored by an agency of the United States Government. Neither the United States Government nor any agency thereof, nor any of their 
employees, makes any warranty, express or implied, or assumes any legal liability or responsibility for the accuracy, completeness, or usefulness of any information, apparatus, product, or process disclosed, or represents that its use would not infringe privately owned rights. Reference herein to any specific commercial product, process, or service by trade names, trademark, manufacturer, or otherwise, does not necessarily constitute or imply its endorsement, recommendation, or favoring by the United States Government or any agency thereof. The views and opinions of authors expressed herein do not necessarily state or reflect those of the United States Government or any agency thereof.

Printed in the United States of America.

This report has been reproduced from the best available copy.

Available to DOE and DOE contractors from the Office of Scientific and Technical Information, P. O. Box 62, Oak Ridge, Tennessee 37831; prices available from (615) 576-8401, FTS 626-8401.

Available to the public from the National Technical Information Service, U. S. Department of Commerce, 5285 Port Royal Rd., Springfield, Virginia 22161.

A prime contractor with the United States

AlliedSignal Inc.

Federal Manufacturing

\& Technologies

P. O. Box 419159

Department of Energy under Contract Number

Kansas City, Missouri

$64141-6159$

DE-ACO4-76-DP00613.

KCP-613-6078

Distribution Category UC-706

Approved for public release; distribution is unlimited.

\section{OPTIMIZATION OF ULTRASONIC FABRIC CLEANING}

T. E. Hand 
Published May 1998

Final Report/Project Accomplishments Summary

CRADA Number 96-KCP-1044

\section{$\Delta$ AlliedSignal}

\section{Optimization of Ultrasonic Fabric Cleaning}

Project Accomplishments Summary

CRADA Number 96-KCP-1044

Date: April 15, 1998

Revision: 0

\section{A. Parties}

The project is a relationship between

AlliedSignal FM\&T

2000 E $95^{\text {th }}$ Street

PO Box 419159

Kansas City, MO 64141-6159
Garment Care, Inc

2018 Swift

North Kansas City, MO 64116

and with additional help from:

Amway Corporation

PO Box 1

Ada, MI 49355-0001 


\section{B. Background}

Traditionally, the dry-cleaning industry has used large amounts of labor and energy to clean and process clothing. Efforts are under way to improve the dry-cleaning process; however, most suggested alternatives propose to only replace cleaning fluids without significantly reducing labor and energy. Research performed in KCP-94-1006, An Environmentally Conscious Approach to Clothes Maintenance, demonstrated that ultrasonic aqueous cleaning systems may potentially be able to replace traditional drycleaning with a new, environmentally friendly process capable of cleaning and processing ALL clothing and linens at much lower cost. Further investigation, however, is still required.

This project, 96-KCP-1044, was performed to allow optimization of the ultrasonic cleaning processes. Success would enable a change in the fundamental methods by which garment maintenance providers handle consumer's clothing.

Garment Care, Inc. is a retail provider of garment maintenance services including laundry and dry-cleaning. Garment Care's president, David Porter, is well known in the industry as a proponent of change; in other words, do it faster, better, and cheaper. AlliedSignal's strength comes from experience with ultrasonic aqueous processing of weapon components and a philosophy of doing things safer and more efficiently. Together, the team, with assistance from scientists at Amway in Ada, Michigan, had the capability to study this next generation of cleaning processes.

\section{Description}

The fundamental purpose of this project was to research and develop a process that would reduce the cost and improve the environmental efficiency of the present dry-cleaning industry. This second phase of research (see report KCP-94-1006 for information gathered during the first phase) was intended to allow the optimal integration of all factors of ultrasonic fabric cleaning. For this phase, Garment Care performed an extensive literature search and gathered data from other researchers worldwide. The Garment CareAlliedSignal team developed the requirements for a prototype cleaning tank for studies and acquired that tank and the additional equipment required to use it properly. Garment Care and AlliedSignal acquired the transducers and generators from Surftran MartinWalter in Sterling Heights, Michigan. Amway's Kelly Haley developed the test protocol, supplied hundreds of test swatches, gathered the data on the swatches before and after the tests, assisted with the cleaning tests, and prepared the final analysis of the results. AlliedSignal personnel, in conjunction with Amway and Garment Care staff, performed all the tests. Additional planning is under way for future testing by outside research facilities.

The final results indicated repeatable performance and good results for single layered fabric swatches. Swatches that were cleaned as a "sandwich," that is, three or more layers 
stacked together, were not as successful. A Final Report will be issued by Garment Care highlighting all the technical details and results of this study.

Amway was invaluable to the project because of their experience in the laundry arena. They have some of the most advanced testing facilities and experienced people available in this country. Their input proved mandatory for determination of the tests required and interpretation of the results. Garment Care's David Porter knows the industry and what is required for consumer satisfaction. His experience allowed determination of those needs from a technical perspective. AlliedSignal brings many years of ultrasonic cleaning knowledge and experience with the latest equipment. Together, the team worked as a unit on this difficult project.

\section{Expected Economic Impact}

First and foremost, this project brought worldwide focus to the likelihood that a revolutionary new system for cleaning and processing clothing is possible. Specifically, since it was discovered that an American branch of a renown German research institute -The Fraunhofer Gesellschaft -- had done similar research, the results of the AlliedSignal/Garment Care project has helped reinforce Fraunhofer's dedication toward continued development. When that development is complete, it is anticipated that a renewed and growing family laundry industry will help alleviate the tedious chore of consumer garment maintenance.

\section{E. Benefits to DOE}

This project required the use of a new style of ultrasonic transducers; the "Push-Pull," offered by Martin-Walter ultrasonics. These are cylindrical-style transducers that radiate vibrations differently than traditional rectangular transducer packs. The AlliedSignal staff quickly found an internal application. This same style was chosen to be used in a facility used for cleaning reservoir components. No testing has been completed on the new facility but indications are the transducers have a good chance for success.

Working together enabled both Garment Care and AlliedSignal personnel to understand the great efforts put into consumer testing of detergents, cleaning methods, and equipment. Applications of these methods to AlliedSignal products are expected and, in fact, have already been used for research on weapon component cleaning process evaluations.

Single entities, like Garment Care, AlliedSignal, or Amway, could not have performed the testing individually. It took a combination of backgrounds and expertise from all parties.

Further research into Ultrasonic Cleaning of Fabrics is planned by Fraunhofer Institute in Florida as a direct result of this CRADA. Plans have already been drawn up for future work; only funding is slowing this research from being completed. 
F. Industry Area

Consumers will benefit from an improved method of garment maintenance. Reductions in energy and water usage will benefit all. Reduction in cost will help garment maintenance companies improve performance and increase revenue, allowing further innovation and increased employment.

\section{G. Project Status}

Delays were carried through the project because of job responsibility changes at Amway and concerns early on regarding potential patent conflicts. The project was completed as planned and a full report will be available from Garment Care offering all the details of the entire process testing.

H. Point of Contact for Project Information

Ken Bauer

US Department of Energy

Kansas City Area Office

PO Box 410202

Kansas City, MO 64141-0202

Telephone: (816) 997-3917

Fax: (816) 997-5059
Tom Hand

AlliedSignal

PO Box 419159

Kansas City, MO 64141-6159

Telephone: (816) 997-3614

Fax: (816) 997-7081

\section{Company Size and Point of Contact}

The principal investigator from Garment Care was David Porter. Garment Care has annual sales of slightly more than $\$ 500,000$ and has 13 employees. The phone number is 816 221-1066; the fax is 816-221-1067.

\section{J. Project Examples}

Attachment A shows a schematic diagram of the system and a proposal that lists details remaining to be studied prior to commercialization. 


\section{K. Technology Commercialization}

Attachment A is a proposed commercialization plan to be developed by Fraunhofer Technology Center in Hialeah, Florida. Presuming it is successfully developed, much of the credit will go to the AlliedSignal/Garment Care project.

\section{Release of Information}

I have reviewed the attached Project Accomplishment Summary prepared by AlliedSignal and agree that the information about our CRADA may be released for external distribution.

Original signed by David Porter 4-27-98

Name: David Porter Date

Organization: Garment Care, Inc.

Title: President

Attachment A

x 


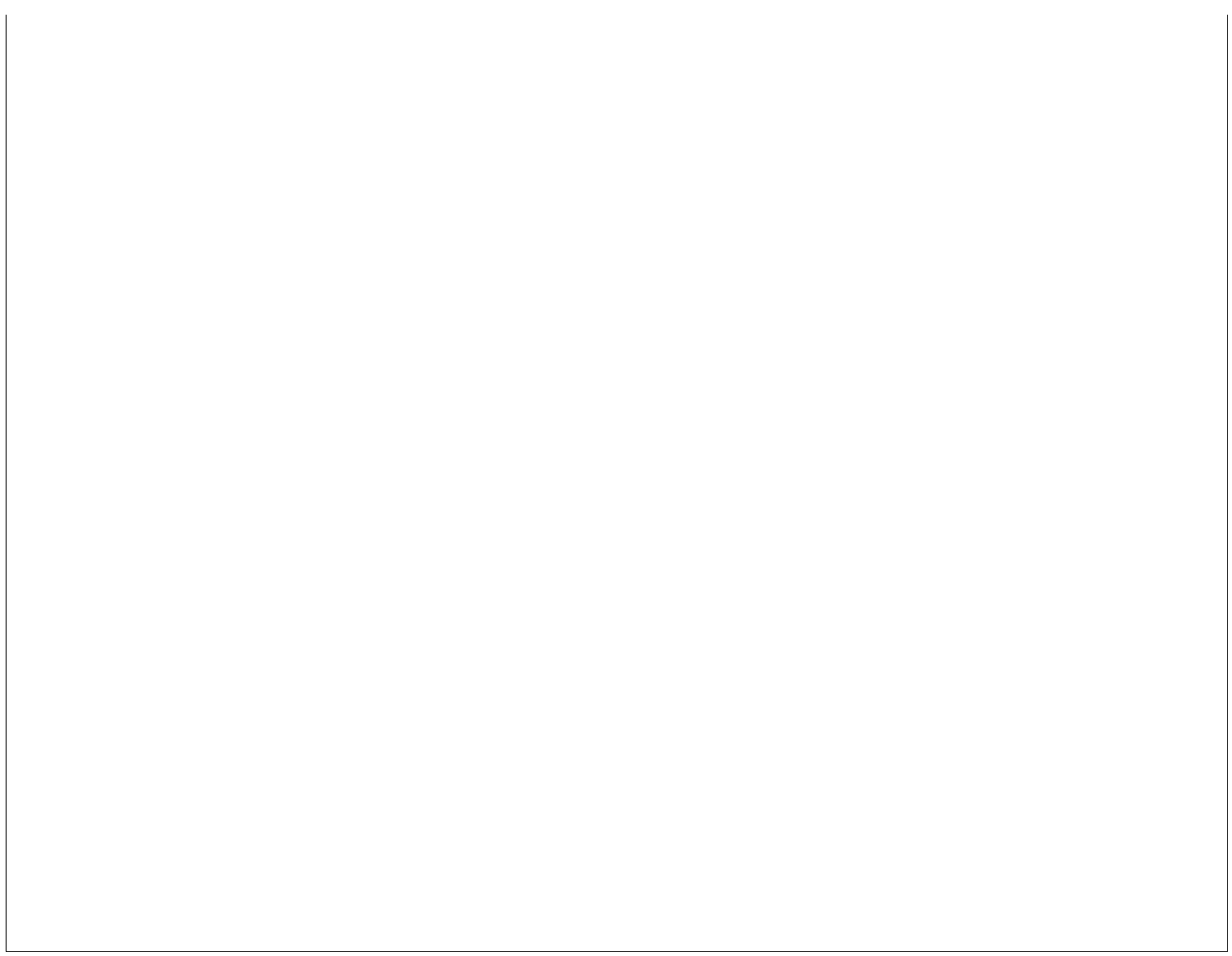

$x$ 


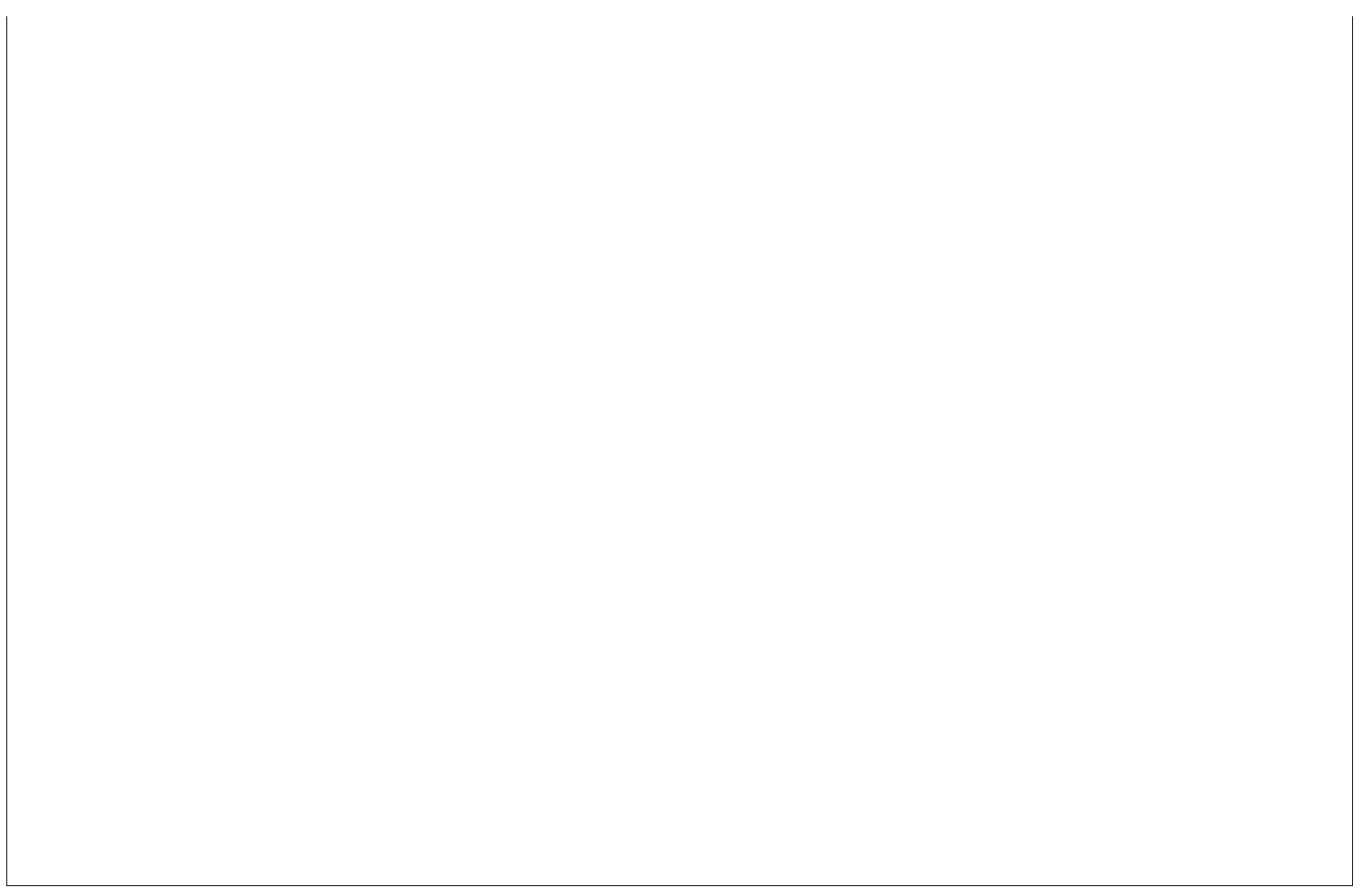

$x$ 


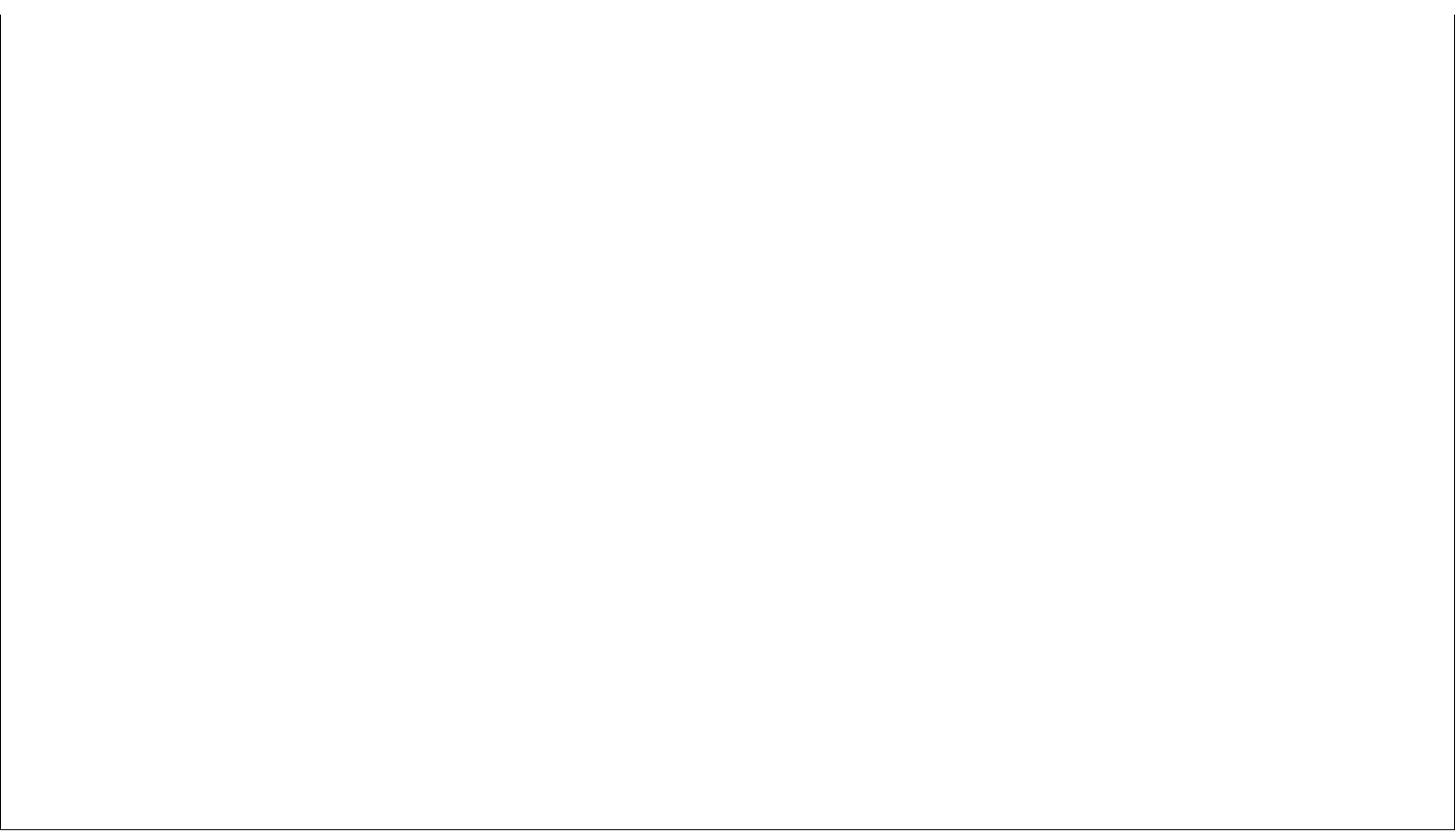

$x$ 
